\title{
Renewable energy technologies on the path towards decentralized low-carbon energy systems
}

\author{
Natalya Danilina ${ }^{1 *}$, Irina Reznikova ${ }^{1}$ \\ ${ }^{1}$ Institute of Engineering and Environmental Security, Togliatti State University, Belorusskaya str. 14, \\ 445020 Togliatti, Russian Federation
}

\begin{abstract}
Renewable energy technologies (RET) that emerged as a result of the shift towards the renewable energy sources (RES) which aims at setting the path towards decentralized low-carbon energy systems intended for tackling global warming are becoming key elements of the smart grids of the future. Our paper applies the economic, social and technological model of the renewable energy platforms to the energy markets of the $21^{\text {st }}$ century. The paper analyses the growing importance of the individual players (prosumers) on the energy market, especially when it comes to the renewable energy generation and trading. It shows that modern advanced information and communication technologies enabled the energy prosumers to trade their energy and information in two-way flows. All of these might be important for the transition towards sustainable economy and green technology.
\end{abstract}

\section{Introduction}

The switch to renewable energy is made possible by technological advances and a societal push towards sustainability, but it is not without its challenges. The gradual transition from the fossil energy to the renewable energy sources means that oil, gas, and coal will remain the dominant energy source for at least the next few decades $[1,2]$. This means that the increase in energy demand for fossil fuels is likely to peak in a generation or more, allowing traditional and established energy companies to continue to thrive. The global energy sector does not face the prospect of painful changes in the short term, but the Paris Agreement's climate targets are absent from the transition scenario. However, in many countries (like the United States), renewable energy and $\mathrm{CO}_{2}$ emissions, which may have peaked last year, are unlikely to meet the goal of a Paris climate agreement $[3,4]$.

Wind and solar power technologies have achieved the wide popularity among all renewable energy sources because they are the most attractive economic alternatives and because government subsidies that support their fleet ramp-up are being phased out $[5,6]$. The growth of renewables is displacing coal, and wind and solar power have already begun to influence the development of new coal-fired power plants. Other energy sectors such as

\footnotetext{
*Corresponding author: danilina@tltsu.ru
} 
natural gas, oil and coal will remain relatively stable. As a result, renewable energy is facing the same challenges as other energy sectors such as natural gas, oil, and coal, but with different challenges $[7,8]$.

Technology can play a key role in addressing the challenges of long-term energy storage and regulating the ups and downs of renewable energy supply. Renewable energy technologies such as wind, solar, hydropower, geothermal, biomass, biofuels, wind turbines, hydropower and solar photovoltaics offer the opportunity to accelerate the transition to renewable energy, while increasing synthetic fuel production and reducing fossil fuel emissions in sectors ranging from steel to food production, chemical industry and fertilisers [9].

Moreover, technological improvements and economies of scale have made renewable energy cost-effective - and competitive with fossil fuels, even without subsidies. This has created the conditions for the production of clean energy to be promoted by low-carbon energy sources such as wind, solar and geothermal energy. New solar plants are approaching cost parity for fossil-fuel power generation, and wind is already competitive which makes the renewable energy more than viable.

\section{Smart grids and energy platforms}

A smart grid is an electricity grid that uses digital technologies to create a more efficient, reliable and cost-effective power distribution system [10]. Nowadays, smart grid approach is implemented by load organizations, but getting the technologies that are most suitable and convenient can be a demanding task. They have several advanced features that ensure reliable network organization. The current electricity distribution network is under pressure due to the increasing energy consumption and rapidly increasing demand for energy using renewables and some novel approaches to producing and transferring energy [11]. Table 1 that follows show some examples of the renewable energy platforms operating as a part of smart grid in several European Union countries as well as the United Kingdom and United States.

Table 1. Examples of the renewable energy platforms

\begin{tabular}{|l|l|l|l|}
\hline \multicolumn{1}{|c|}{ Platform } & Country & \multicolumn{1}{|c|}{ Novelty } & \multicolumn{1}{c|}{ Pricing } \\
\hline $\begin{array}{l}\text { Enyway } \\
\text { www.enyway.com }\end{array}$ & Germany & $\begin{array}{l}\text { Intermediary etween } \\
\text { renewable } \\
\text { producers and customers }\end{array}$ & $\begin{array}{l}\text { Traditional contract } \\
\text { with a combination of } \\
\text { kWh-prices dependent } \\
\text { on the suppliers }\end{array}$ \\
\hline $\begin{array}{l}\text { SonnenCommunity } \\
\text { https://sonnenbatterie.de }\end{array}$ & Germany & $\begin{array}{l}\text { Stable power supply } \\
\text { utilizing batteries and } \\
\text { provision of surplus power } \\
\text { pool }\end{array}$ & $\begin{array}{l}\text { Sales of batteries to } \\
\text { prosumers }\end{array}$ \\
\hline $\begin{array}{l}\text { Vandebron } \\
\text { www.vandebron.nl }\end{array}$ & Netherlands & $\begin{array}{l}\text { Offering green energy from } \\
\text { local suppliers ("know your } \\
\text { clean energy supplier") }\end{array}$ & $\begin{array}{l}\text { Monthly subscription } \\
\text { fee for providers and } \\
\text { consumers }\end{array}$ \\
\hline $\begin{array}{l}\text { Piclo } \\
\text { www.openutility.com/piclo }\end{array}$ & $\begin{array}{l}\text { Government-supported } \\
\text { information service that } \\
\text { helps to match the } \\
\text { kreferences of renewable } \\
\text { energy providers, energy } \\
\text { consumers and distribution } \\
\text { use of service }\end{array}$ & $\begin{array}{l}\text { Supported by the UK } \\
\text { government } \\
\text { venture capital and }\end{array}$ \\
\hline
\end{tabular}




\begin{tabular}{|l|l|l|l|}
\hline $\begin{array}{l}\text { Mosaic } \\
\text { www.solarmosaic.com }\end{array}$ & $\begin{array}{l}\text { United } \\
\text { States }\end{array}$ & $\begin{array}{l}\text { Peer-to-peer solar power } \\
\text { platform with the } \\
\text { possibility for everyone to } \\
\text { join and become a local } \\
\text { solar contractor }\end{array}$ & $\begin{array}{l}\text { Flat monthly payment } \\
\text { for prosumers }\end{array}$ \\
\hline
\end{tabular}

All around the world, stakeholders and policymakers want to simplify the control of a smart grid from the perspective of companies and homeowners with its prosumer solution. With tailored software, prosumers can help create demand programs, manage, automate, and automate their use, and improve overall reliability of power supply, making them more efficient and reliable. Such systems are not only going provides uninterrupted power, but also to work at lower cost, reducing the carbon footprint $[12,13]$.

With regard to this shift, it is predictable that traditional network companies, which face limited customer exodus, will try to become leaner by using new digital technologies to improve operational efficiency. Some companies claim to be able to create a self-renewing network using its smart grid technology and smart contracts. Operators must become system stabilisers in markets where the level of decentralised generation is moderate to high and where consumers maintain their grid connectivity by selling surplus electricity into the grid. Energy aggregation platforms bring decentralized energy sources to a single platform, allowing clusters of generators to operate like a large power plant. Investing in smart technologies would enable to dynamically balance demand and supply in real time. Managing demand from intermittent renewable energy sources and demand for intermittent renewable energy from all sources can be achieved. A typical example of such a platform is a virtual power plant. Such a plant allows renewable energy sources to be integrated and avoids the usual pitfalls of scalability and predictability $[14,15]$.

Virtual power plants enable the system to be optimised on the basis of regional - specific grid requirements and can supply economically produced electricity. The platform can store excess electricity and, if required, supply it, balancing the grid. Energy companies develop renewable energy site and grid modelling software that delivers faster and more accurate results than traditional solutions. The software was described as a utility - out-of-the-box solution that provides a solution for renewable and non-renewable energy systems. Sustainable energy strategy aims for an energy and internet network that includes smart grids, smart power plants and smart energy storage.

These approaches are being implemented in many countries but the real showcase would be Germany that is now at the forefront of implementing and using the green energy technologies and renewable energy. The transformation of the German energy supply system is one of the greatest current and future challenges for Germany $[16,17]$. This is because the sector is becoming more flexible in managing the demand and supply of electricity. The socalled "smart grid" of the future will be able to better match fluctuating renewable energy sources with demand in the future and vice versa. The smart grid is designed as a modernised electricity grid that facilitates mutual digital communication between suppliers and consumers through an intelligent measurement and monitoring system that receives and transmits information. This will enable 'smart grids' to control the flow of energy from renewable energy sources such as wind, solar and hydropower, and to use AI to collect measurement data and provide consumer information. This allows business processes for energy retailers, energy suppliers and network operators to be automated.

\section{Citizens participating on the energy transition}

In order to achieve such transitions, it is essential that the public is involved constructively, one needs to analyse this commitment through the concept of energy dialogue 
and energy citizenship. Citizenship in the energy field is created through policy making and planning, with potential measures marked by the need to address issues such as climate change, energy security, renewable energy and the future of the economy [18]. In a large part of the focus groups and interviews, many participants discussed how dependent they are on fossil fuels, as opposed to others who prefer renewable energy technologies. This should include the energy dialogue which covers a range of issues such as energy security, climate change, energy efficiency and the role of renewable energy in the economy [19, 20].

From an instrumental, moral and ethical perspective, it is important to involve the entire socio-economic spectrum in the transition to low-carbon technologies. On the instrumental side, this would help to avert or mitigate the profound social adjustment that will inevitably lead to social unrest, and reduce resistance to proposed transitional solutions. If decentralised energy is to play a major role in the transition to a low-carbon future, the implementation community must be supported by a more effective approach to public engagement. The results presented show that this was initially unsuccessful in several respects. Specifically, it is about the shortcomings that occur before renewable energy systems are installed, about the lack of support for residents and about whether we can effectively solve the problems that arise after implementation. It is clear that there are concerns, but they are ineffective and bad practices that do not take into account the subtleties and needs of any community.

In the same time, renewable energy solution involving regular prosumers might be very advantageous and profitable, since the profit that the traditional energy companies are generating is removed from the scheme. One can see the difference using the example from the renewable energy pricing by Vandebron.nl, a company from the Netherlands [21] (see Figure 1 below).

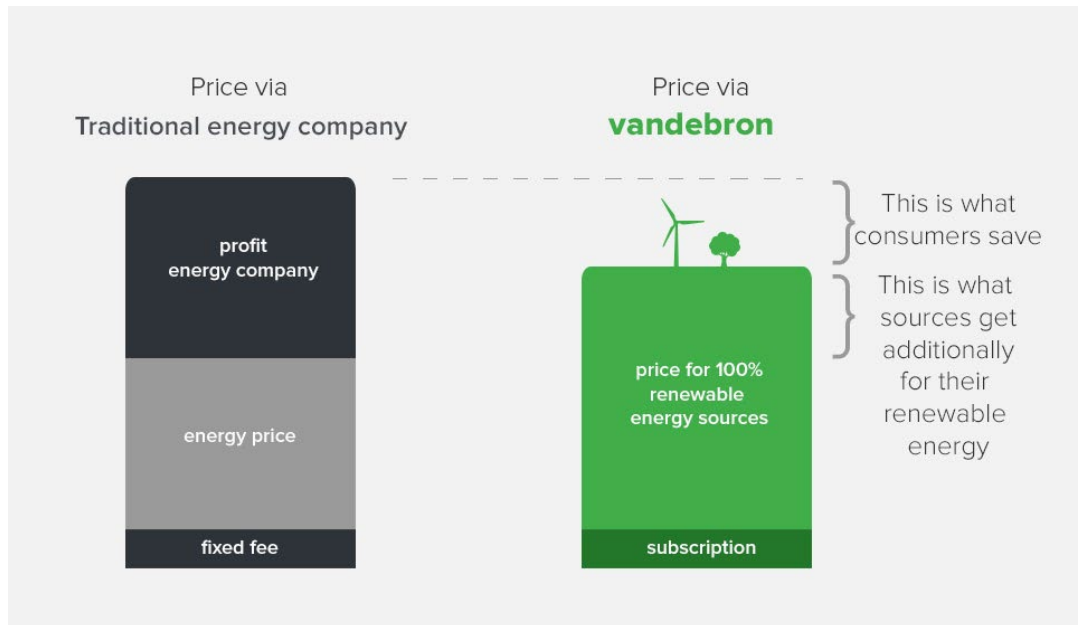

Fig. 1. Advantages of the renewable energy for the consumers on the example of vandebron.nl

This approach, while laudable, implies real challenges in terms of public participation. We have an approach that says that there is an urgent need to tackle new renewable energy projects, which need to be more transparent and transparent than traditional fossil fuel electricity generation.

Increased use of renewable energy sources such as wind, solar and geothermal will help ensure that each country has secure energy supplies and reduce greenhouse gas emissions to slow climate change and boost investment, new jobs and business. Many local planning authorities are legally required to set up advisory councils and are responsible for planning, building and installing new and installed renewable energy capacity. Planning plays a role in 
selecting sites where local environmental impacts are acceptable. Local planning authority is typically a statutory advisory body with a considerable annual budget for planning and planning services. It is clear that the contribution that decentralised local energy solutions can make to the development of renewable energy and the decarbonisation of the energy system in the context of the national renewable energy plans can have long-range impacts on the development of the low-carbonized future renewable energy systems [22]. While new business models challenge traditional large energy providers, we say we are pursuing similar innovations. As businesses and cities move forward, current market designs and existing regulations are not yet ripe for more decentralized energy models. There are obstacles that mean that there is no level playing field, but decentralised projects can be implemented because they are an inherently cost-effective form of infrastructure. The operating costs of a renewable energy project are much lower than they would be if there were no direct fuel costs associated with fossil fuel production such as coal, oil, and gas. A small, low-cost renewable power plant in a small district could be a great advantage for neighbouring counties as a source of low-cost electricity.

\section{Digital platforms and the Internet of Energy}

The state narrative links the development of the electricity sector to modernity, energy security, and industrialization and normalizes the temporal need for coal by providing an incentive to strengthen fossil-fuel-based infrastructure when newly planned coal-fired power plants go online. This state narrative, coupled with the declared mitigation of climate change through state-directed direct management of the energy sector, is justified by the need to achieve the "green" agenda. The tension between these seemingly contradictory goals seems to have been resolved by portraying it as a conflict between the state and the private sector over the future of electricity generation and consumption.

Digital industrial platforms are crucial because they capture data from machines, make it accessible for monitoring and controlling applications, enable third parties to develop databased applications and connect different users and application developers. These platforms will be crucial for energy service providers to provide consumers with data services and to use new technologies such as electric vehicle charging to pave the way for maximising the use of renewable energy and decarbonising energy. Digital industrial platforms can also be used to support farmers by combining location data with data from the Internet of Things (IoT) and field sensors, allowing seeds and optimal water use to be adapted to specific fields to ensure efficient productivity (as well as the Internet of Energy (IoE) which is a part of the IoT and includes all electrical devices, sensors and smart meters connected to the Internet or linked within the smart grid) [23, 24]. In this way, the ongoing COVID-19 pandemic has accelerated the development of a digital industrial platform in which the utilities industry plays a central role in providing sustainable services to consumers. Digital industrial platforms can ultimately be equipped with the appropriate business models. The industry that enables regulators has taken risks and adapted to new standards by using new technologies and new business models such as smart meters, smart grids and smart grid systems. Some IoT platforms are touted as those that promote secure and reliable power supplies, with the industry trying to question itself and explore the possibilities. Regulators will play a key role in creating the platform that will enable us to remove these barriers. The platform is also remarkably popular with entrepreneurs, investors and private companies. There are also a number of examples of how to harness the power of community networks to develop business. In the next phase, known as "cloud computing", the IT companies' unique software architecture, which enables faster and more efficient deployment of technologies that are easily scalable across the company, is designed to accelerate the evolution into a platformbased company [25]. To shape the future, rather than waiting for it, our innovation centres 
are trying to harness innovation by supporting start-ups in technologies with significant potential. Digital platforms are increasingly regulated, with Japan the latest country to pass new laws to regulate their operation. They work with local investors, scientists, governments and others to find solutions to today's most pressing problems. Governments are also empowered to assess compliance, publish the results of their assessments and take the necessary measures to enforce compliance, including the issuing of fines for infringements. Thence, the role of digital platforms in the future of energy supply in Europe and the United States is very important and the impact of their regulations can be crucial for the development of new technologies such as renewable energies and energy storage. In addition, there is a question of whether the future of distribution system operators lies in the platform business or in the ownership of basic assets. One has to look at the role of digital platforms and the potential impact of the regulatory framework for digital technologies. In a year of continuous change, the energy companies' commitment to improving customer service in the regulated electricity and gas business has remained constant. The strength of the strategy lies in the combination of our many strengths as we continue to create the most efficient, efficient and competitive distribution network operators. This might help to overcome the challenges and strengthen energy customers now and in the future. To make smart networks smarter and more resilient and keep pace with growth, investments in new renewable energy technologies such as smart grids, smart electricity poles and meters, smart meters and new infrastructure, should be generous and ongoing. The investment in people, systems and digital platforms might also enable energy companies to streamline the installation process to conveniently meet service agreements and enable meter installations to scale consistently and reliably.

\section{Conclusions and policy implications}

In the conclusion, we can say that people need to take control of their own energy future and invest in a decentralized network that lowers prices, improves energy security, reduces carbon emissions, and makes their communities more prosperous and resilient. Decentralised energy is not yet a commonly understood concept, but it broadly refers to energy produced outside the main grid, including micro-renewable heating and cooling systems. It can cover any energy and the use of a combined heat and power plant will fuel competition as the number of energy suppliers increases. This allows energy-consuming communities to be integrated into a single energy system, such as a power plant or heating and cooling system. If consumers also become both energy producers and prosumers, the system would lead to a decline in electricity generation when old power plants are obsolete. Consumers could then sell electricity back into the grid, offering a way to supply a national grid with backup electricity.

The growing importance of the prosumers on the energy market, especially when it comes to the renewable energy generation and trading is becoming a reality thanks to the advanced information and communication technologies which enable these prosumers to trade their energy and information in two-way flows similar to the principles of the sharing economy. People were ready to accept Airbnb and Uber, so they might be also fine with the peer-topeer energy sharing networks. All of these might be important for the transition towards sustainable economy and green technology.

In addition, it becomes apparent that the existing forms of social engagement do not generate the speed and scale of change required for the transition from the fossil-based economy to the ones based on the renewable energy sources. The main reason might be the lack of public participation in the development and implementation of new energy technologies. For example, houses, wind turbines, solar power plants and wind farms, as well as solar thermal power plants. A more connected approach will give policymakers the evidence they need to properly address the concerns of different citizens, recognize that low- 
carbon policies often disappear under the radar, and capitalize on the synergies of otherwise isolated public engagement.

\section{References}

1. D. Jie, X. Xu, F. Guo, Energy, 220, 119644 (2021)

2. I. Sotnyk, I. Shvets, L. Momotiuk, Y. Chortok, Marketing and Management of Innovations, 4, 150-160 (2018)

3. M.N. Dudin, E.E Frolova, O.V. Protopopova, A.A. Mamedov, S.V. Odintsov, Entrepreneurship and Sustainability Issues, 6(4), 1704-1713 (2019)

4. W. Strielkowski, E. Lisin, I. Gryshova, Romanian Journal of European Affairs, 16(4), 68-77 (2016)

5. P. Joskow, Oxford Review of Economic Policy, 35(2), 291-331 (2019)

6. F. Van Triel, T. Lipman, Energies, 13(20), 5277 (2020)

7. G. Chebotareva, W. Strielkowski, D. Streimikiene, Journal of Cleaner Production, 269, $122110(2020)$

8. C. Magazzino, M. Mele, N. Schneider, Energy, 219, 119586 (2021)

9. M. Javed, T. Ma, J. Jurasz, M. Amin, Renewable Energy, 148, 176-192 (2020)

10. F. Al-Turjman, M. Abujubbeh, Future Generation Computer Systems, 96, 579-590 (2019)

11. M. Buth, A. Wieczorek, G. Verbong, Energy Research \& Social Science, 53, 194-205 (2019)

12. M. Lovati, X. Zhang, P. Huang, C. Olsmats, L. Maturi, Buildings, 10(8), 138 (2020)

13. S. Sharda, M. Singh, K. Sharma, Sustainable Cities and Society, 65, 102517 (2020)

14. P. Dey, D. Das, A. Latif, S. Hussain, T. Ustun, Sustainability, 12(17), 6979 (2020)

15. L. Ju, Q. Tan, H. Lin, S. Mei, N. Li, Y. Lu, Y. Wang, Energy, 196, 117078 (2020)

16. M. Sait, U. Chigbu, I. Hamiduddin, W. De Vries, Resources, 8(1), 7 (2019)

17. K. Hansen, B. Mathiesen, I. Skov, Renewable and Sustainable Energy Reviews, 102, 113 (2019)

18. D. Brown, S. Hall, M. Davis, Energy Research \& Social Science, 66, 101475 (2020)

19. I. Cabelkova, W. Strielkowski, I. Firsova, M. Korovushkina, Energies, 13(7), 1742 (2020)

20. R. Ostfeld, D. Reiner, Energy Policy, 140, 111332 (2020)

21. C. Park, T. Yong, Energy Procedia, 128, 3-9 (2017)

22. C. Nolden, J. Barnes, J. Nicholls, Renewable and Sustainable Energy Reviews, 122, $109722(2020)$

23. M. Ayaz, M. Ammad-Uddin, Z. Sharif, A. Mansour, E. Aggoune, IEEE Access, 7, 129551-129583 (2019)

24. S. Marzal, R. González-Medina, R. Salas-Puente, G. Garcerá, E. Figueres, IEEE Internet of Things Journal, 6(4), 7241-7252 (2019)

25. N. Hossein Motlagh, M. Mohammadrezaei, J. Hunt, B. Zakeri, Energies, 13(2), 494 (2020) 